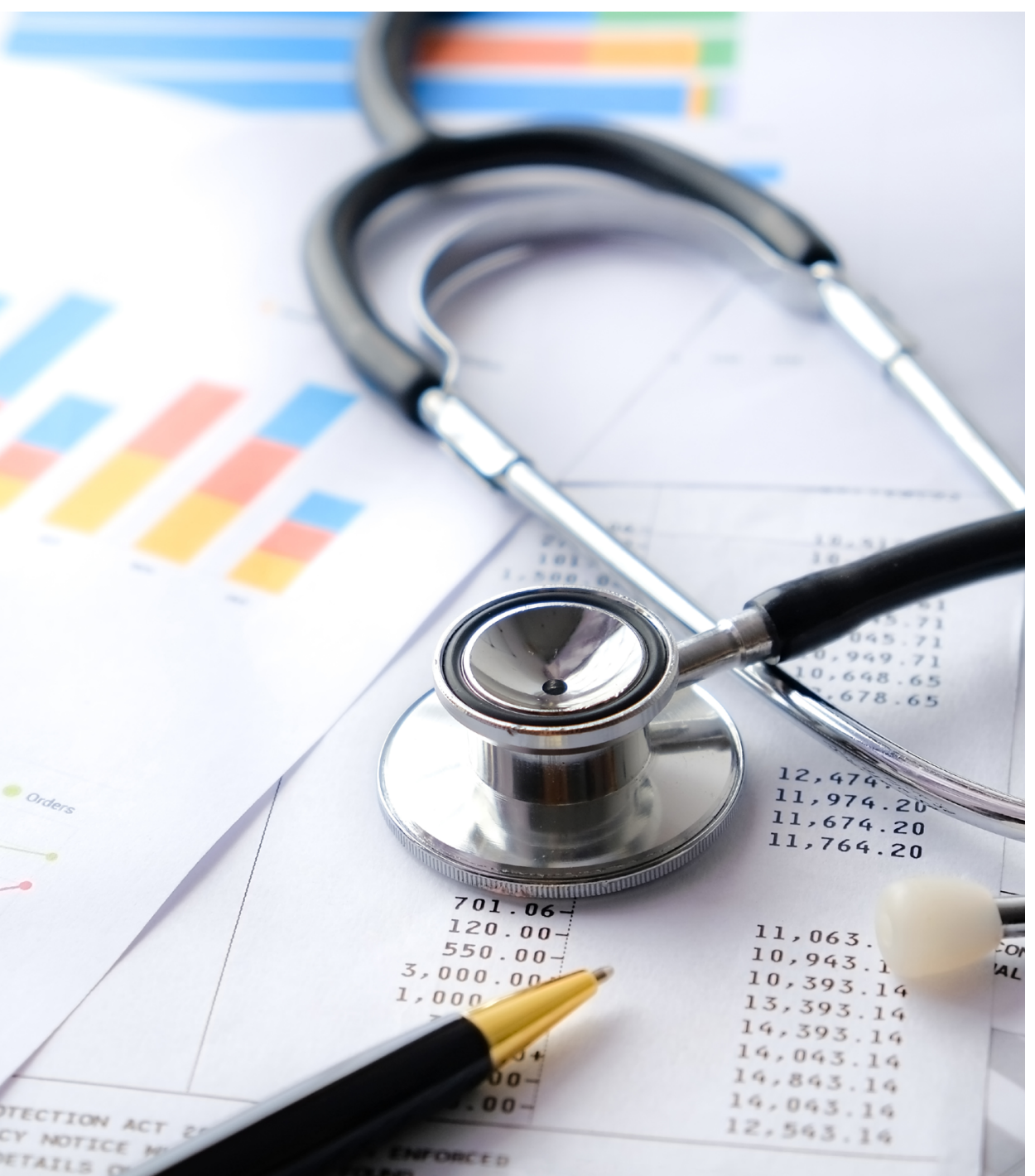

\title{
VALE A PENA INVESTIR NA ACREDITAÇÃO HOSPITALAR?
}

ESTUDOS INDICAM MELHORIAS EFETIVAS EM IMPORTANTES INDICADORES DA GESTÃO, BENEFICIANDO A INSTITUIÇÃO E OS PACIENTES. AS PERSPECTIVAS SÃO POSITIVAS, MAS TAMBÉM DEVEM SER CONSIDERADAS AS LIMITAÇÕES DAS PESQUISAS ANALISADAS. 


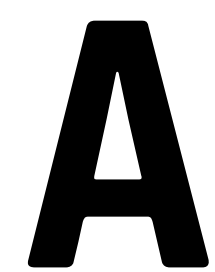

qualidade da assistência, a eficiência e a segurança do paciente devem ser constantemente perseguidas pelos gestores hospitalares, mas como assegurar o uso eficiente dos recursos investidos nessas iniciativas? A acreditação surgiu como forma de responder a essa questão. Conduzida por organizações independentes, ela inclui, normalmente, a seleção de padrões e requisitos a serem seguidos, o treinamento de funcionários e o acompanhamento de implementação, com identificação de aspectos que precisam de melhorias.

Trata-se de um processo que demanda tempo e dinheiro das instituições hospitalares e sobre o qual se deposita grande expectativa de resultados positivos. No entanto, os resultados não são imediatos e, por vezes, são difíceis de serem mensurados, por não ser simples isolar variáveis e atribuir as melhorias alcançadas unicamente à obtenção da acreditação. Além disso, o caminho é dinâmico, podendo evoluir de um estado inicial sem certificação para diferentes estágios de acreditação, nacional e internacional, impactando a eficiência e a qualidade dos hospitais ao longo dessa jornada. Todos esses fatores geram dúvida sobre os benefícios efetivamente alcançados com a acreditação hospitalar.

Foi essa questão que motivou um estudo sobre o impacto da acreditação nos indicadores de qualidade dos hospitais, realizado em 2020. Foram investigados fatores preconizados pela Organização Mundial da Saúde (OMS), por Avedis Donabedian e pelo Institute of Medicine relacionados às seguintes dimensões da qualidade: segurança, eficiência, efetividade, foco no paciente, equidade, acesso e tempo de entrega (pouca espera). O estudo baseou-se em uma revisão sistemática da literatura em oito bases de dados internacionais, resultando em 943 artigos que tratavam do tema. Apenas 36 deles foram selecionados para análise mais profunda, pois verificavam objetivamente o impacto gerado pela acreditação, comparando indicadores hospitalares antes e depois do processo ou indicadores e hospitais acreditados relativamente a hospitais não acreditados.

\section{RESULTADOS DOS ESTUDOS}

Os artigos analisados reportaram impacto positivo da acreditação em três dimensões: segurança do paciente, eficiência e efetividade. Na dimensão segurança do paciente, observaram-se melhoria nos cuidados baseados em evidências e menores taxas de infecção, de eventos adversos e de incidente de escaras. No que se refere à eficiência, verificaram-se menor rotatividade de pessoal, melhores registros médicos e organização da documentação pela enfermagem, melhores instalações e infraestrutura física, maior satisfação dos profissionais e melhor gestão de resíduos. Por último, no caso da efetividade, auferiram-se menores tempo de permanência dos pacientes, taxa de mortalidade e taxas de readmissão. Esses resultados reforçam alguns aspectos positivos da acreditação, como a padronização de procedimentos, a criação de políticas internas e o estabelecimento de sistemas de gestão. Além disso, a adoção de padrões preestabelecidos e explícitos para orientar os processos de cuidado também pode contribuir para a segurança do paciente, especialmente ao levar em consideração métricas bem definidas, evitando, por exemplo, erros de medicação.

Apenas sete dos 36 artigos (19\%) investigaram indicadores relacionados ao foco no paciente, e os resultados foram divididos. Quatro artigos reportaram não haver impacto da acreditação, enquanto três concluíram existir impacto positivo na satisfação e no respeito aos direitos e à privacidade dos pacientes. Vale refletir sobre esses achados. Será que a acreditação se traduz em qualidade percebida pelos pacientes? Há a necessidade de mais estudos sobre essa questão, mas os resultados dos sete artigos deixam claro que melhorar processos (eficiência) e, consequentemente, aumentar a resolutividade e segurança dos procedimentos (dimensões efetividade e segurança do paciente) não necessariamente se traduzem em qualidade percebida pelos pacientes e familiares.

As dimensões acesso e tempo de espera foram objeto de pouquíssimos estudos, e os resultados apontaram impacto nulo. Por último, não foi localizado nenhum artigo com foco no efeito da acreditação na equidade dos serviços de saúde entregues à população. Essas dimensões são muito importantes para serem deixadas em aberto pelos estudiosos e devem ser objeto de atenção por parte dos gestores do setor, especialmente no Brasil. A falta de acesso e de equidade dos serviços de saúde brasileiros e os longos tempos de espera têm levado à chamada judicialização da saúde - aumento exponencial das ações judiciais visando à obtenção de tratamento - e à crescente pressão da sociedade brasileira por cobertura e tratamento igualitário entre pobres e ricos.

\section{BONS INDÍCIOS, MAS COM RESSALVAS}

Em termos gerais, os resultados indicam que vale a pena todo o dinheiro e tempo investidos para obter o selo da acreditação. O processo tem o potencial de gerar melhorias efetivas em importantes indicadores da gestão hospitalar, beneficiando a instituição e os pacientes, no entanto os resultados devem ser avaliados com cuidado, levando-se 


\section{CRESCIMENTO DO NÚMERO DE HOSPITAIS ACREDITADOS NO BRASIL}

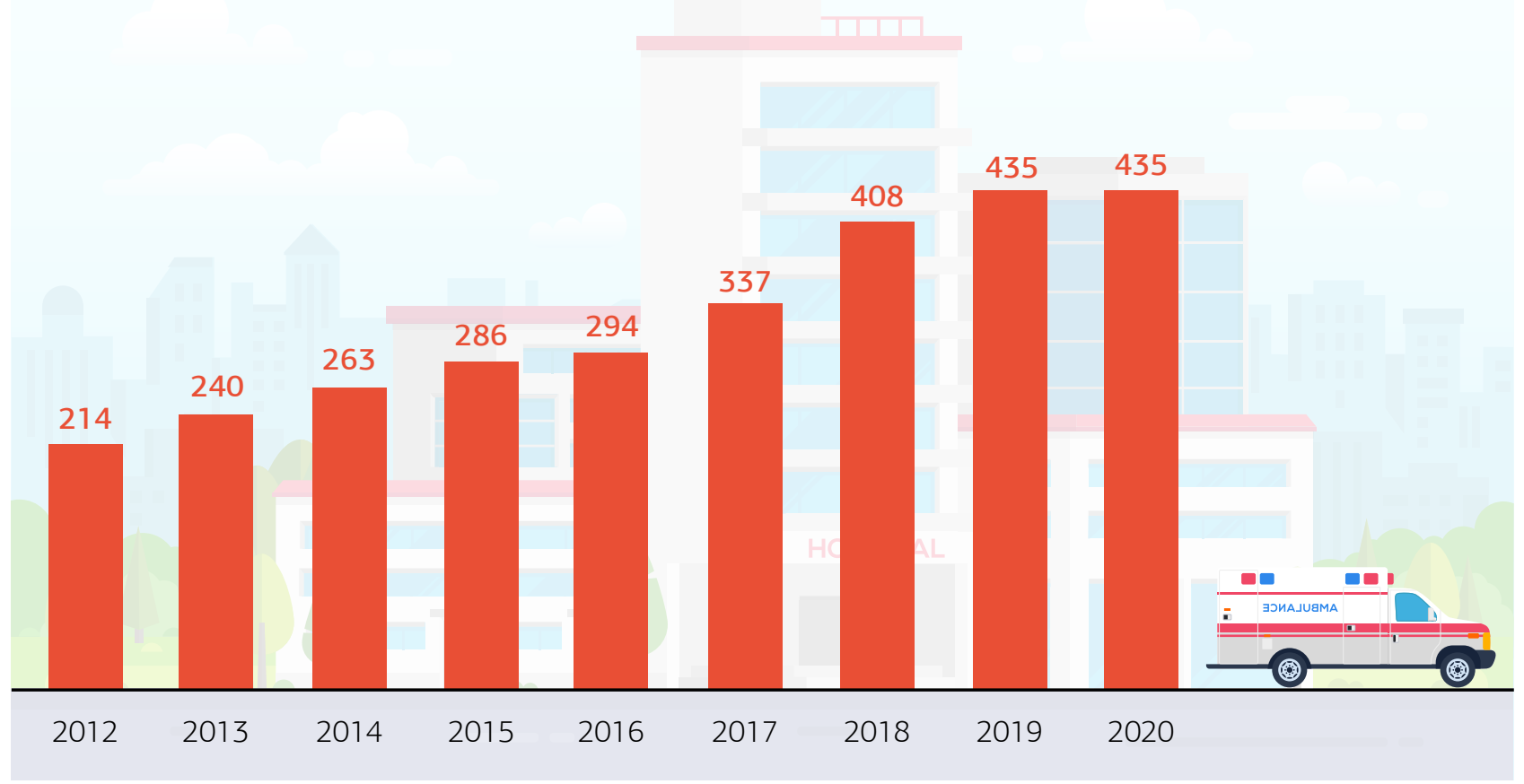

em consideração as limitações metodológicas dos estudos pesquisados.

Os estudos investigaram acreditações distintas e hospitais muito diferentes em termos de número de leitos, país e tipo de hospital. Além disso, a revisão dos estudos mostrou que, por mais esforços que se façam, é de fato grande o desafio de isolar o fator acreditação nos resultados das instituições analisadas, já que outros fatores não controlados podem confundir os resultados.

Para as pesquisas que compararam os resultados de hospitais acreditados versus não acreditados, há ainda outro complicador: não fica claro se os melhores resultados observados nos hospitais acreditados, relativamente aos não acreditados, estão relacionados à acreditação em si, ou se a acreditação apenas revela hospitais mais motivados e preparados para cumprir as diretrizes estabelecidas e obter o selo. Em cenários em que a acreditação é uma escolha, e não uma obrigação, existe a possibilidade de que hospitais com melhores e mais recursos estejam mais prontos para passar por esse processo para confirmar sua excelência.

Da mesma forma, a comparação de períodos pré e pós-acreditação apresenta algumas limitações, não sendo possível atribuir variações nos indicadores necessariamente ao impacto do processo. Quanto mais longo o estudo, maior a chance de que elementos não antecipados interfiram nos resultados. Além disso, dado que a acreditação muitas vezes visa a um processo de melhoria contínua, é difícil definir o ponto-final, dividindo os períodos antes e depois da acreditação, ou definir precisamente a lacuna de tempo entre a intervenção (a acreditação) e o efeito no objeto de estudo (os indicadores de qualidade dos hospitais).

Assim, fica a reflexão: a acreditação melhora os indicadores de qualidade, ou melhores indicadores de qualidade resultam na acreditação da instituição? Em quanto tempo se dá o retorno do investimento? Ou seja, em quanto tempo é possível ver os efeitos do esforço? Por enquanto, o impacto positivo da acreditação nos indicadores de qualidade dos hospitais tem um componente de fé, mas com bons presságios de que, no fim de contas, vale a pena acreditar e investir no processo.

PARA SABER MAIS:

Claudia A. S. Araujo, Marina Martins Siqueira e Ana Maria Malik. Hospital accreditation impact on healthcare quality dimensions: a systematic review. International Journal for Quality In Health Care, v.32, n.8, 2020. Disponivel em: doi.org/10.1093/intahc/mzaa090

CLAUDIA A. S. ARAUJO > Professora do Instituto de Pós-Graduação e Pesquisa em Administração da Universidade Federal do Rio de Janeiro e da FGV EAESP > claraujo@coppead.ufrj.br

ANA MARIA MALIK > Professora da FGV EAESP > ana.malik@fgv.br 